Check for updates

Cite this: RSC Adv., 2019, 9, 39323

\title{
Mechanistic investigation of photocatalytic degradation of organic dyes by a novel zinc coordination polymer $\dagger$
}

\author{
Jianqiang Huo, (D) *a Donghui Yu, ${ }^{a}$ Haiqiang Li, ${ }^{a}$ Bingcai Luo ${ }^{a}$ \\ and Navamoney Arulsamy (DD ${ }^{b}$
}

\begin{abstract}
A new coordination polymer $\left\{\left[\mathrm{Zn}(\mathrm{TIPA})(\mathrm{seb})_{0.5}\right]\left(\mathrm{NO}_{3}\right) \cdot 3.5 \mathrm{H}_{2} \mathrm{O}\right\}_{n}(1)(\mathrm{TIPA}=\operatorname{tris}(4-(1 \mathrm{H}$-imidazol-1-yl)phenyl) amine, seb = sebacic acid) is prepared and characterized by elemental analysis, Fourier transform infrared spectroscopy (FTIR), powder X-ray diffraction (XRD) and single crystal X-ray diffraction. Complex 1 has a three-dimensional (3D) 2-fold interpenetrating diamondoid network, and can be represented by the Schläfli symbol $\left\{3^{3} \cdot 4^{3} \cdot 5^{4} \cdot 6^{4} \cdot 7\right\}$. The luminescent, optical, and thermal properties of 1 in the solid state are investigated. Significantly, 1 assists in the photo-degradation of organic dyes in the presence of $\mathrm{H}_{2} \mathrm{O}_{2}$ and upon irradiation with UV light $(\lambda=254 \mathrm{~nm}$ ). A mechanistic study toward understanding the photocatalytic degradation of organic dye molecules is carried out. The study reveals that the band gap of the fluorophore TIPA is lowered by the charge interaction between the $\mathrm{Zn}^{2+}$ cation and ligand seb ${ }^{2-}$ dianion. The enhanced photocatalysis of 1 is also accompanied by the selective sensing of polar organic solvent nitromethane (NM) and antibiotic ofloxacin (OFX) by a luminescence quenching process. Concurrently, 1 demonstrates excellent ability to adsorb inorganic pollutant permanganate ions likely due to the presence of its unique 3D structural network.
\end{abstract}

Received 26th September 2019 Accepted 23rd November 2019

DOI: $10.1039 / \mathrm{c} 9 \mathrm{ra0} 021 \mathrm{e}$

rsc.li/rsc-advances
When a semiconductor photocatalytic material is irradiated with a light of higher energy than the catalyst's forbidden bandwidth, electrons $\left(\mathrm{e}^{-}\right)$and holes $\left(\mathrm{h}^{+}\right)$are generated on the conduction and valence bands, respectively, leading to photogenerated electron-hole pairs $\left(\mathrm{e}^{-}-\mathrm{h}^{+}\right)$inside the semiconductor. ${ }^{18-21}$

(2) Photogenerated electron-hole pair migration and recombination:

Under the influence of the electric field, photogenerated electrons and holes migrate rapidly to the surface of the semiconductor material. ${ }^{22,23}$ Since photogenerated electrons and holes have a short lifetime and opposing charges, they recombine at the surface, or inside of the material, by electrostatic attraction to release energy.

(3) Surface reaction:

For the process to be effective the photogenerated electrons and holes undergo a redox reaction at the surface. The photogenerated holes can oxidize electron donors such as $\mathrm{OH}^{-}$and $\mathrm{H}_{2} \mathrm{O}$ to hydroxyl radicals $(\cdot \mathrm{OH})$, which have strong redox capabilities, and can interact with organic dye molecules to achieve degradation. ${ }^{24-26} \mathrm{~A}$ schematic representation of the mechanism is shown in Fig. 1.

Zinc-based semiconductor catalysts, including simple oxides and metal complexes, have been shown to effectively degrade organic substances such as dyes in wastewater. ${ }^{27-29}$ Among those, $\mathrm{ZnO}$ is the most commonly used photocatalytic material $^{30-33}$ as it has a high uptake of sunlight with a high quantum
${ }^{a}$ Key Laboratory of Eco-functional Polymer Materials of the Ministry of Education, Key Laboratory of Eco-environmental Polymer Materials of Gansu Province, College of Chemistry and Chemical Engineering, Northwest Normal University, Lanzhou 730070, China. E-mail: huojianqiang@hotmail.com

${ }^{b}$ Department of Chemistry, University of Wyoming, 1000 E University Ave, Laramie, WY 82071-2000, USA

† Electronic supplementary information (ESI) available. CCDC 1967331. For ESI and crystallographic data in CIF or other electronic format see DOI: 10.1039/c9ra07821e 


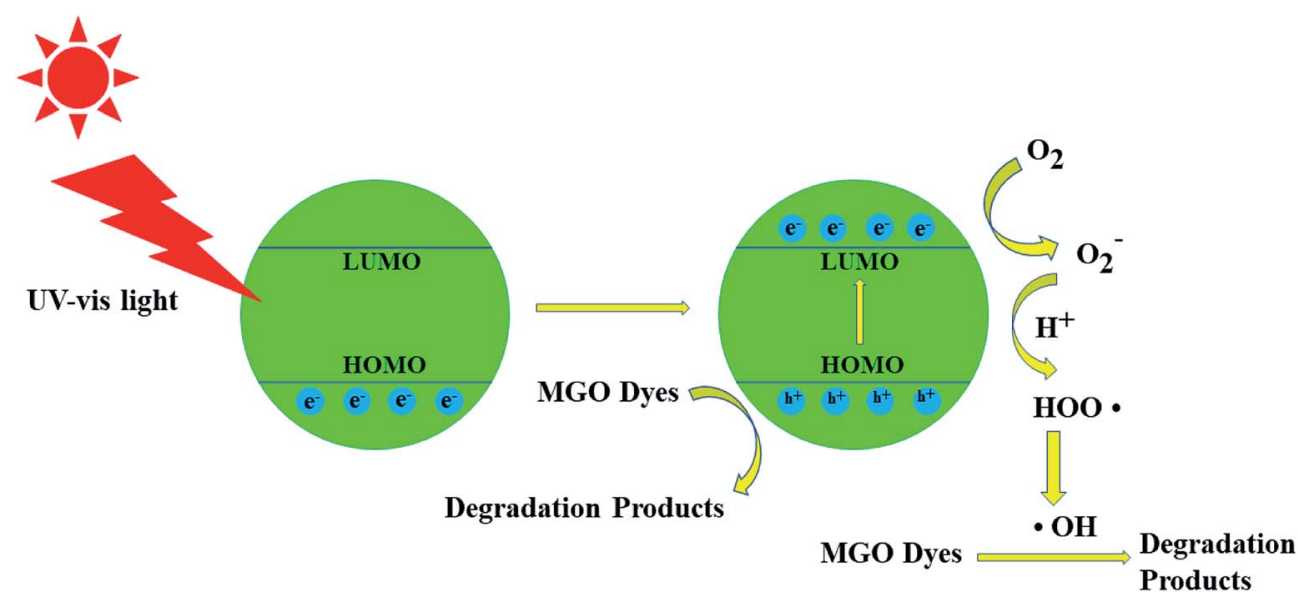

Fig. 1 Schematic diagram of the proposed mechanism for malachite green oxalate (MGO) photocatalytic degradation over the fluorophore compounds.

yield. More intricate complexes such as $\mathrm{Zn}(\mathrm{INA})_{2}$ (INA $=$ isonicotinic acid $)^{34}$ demonstrate better photocatalytic properties compared to ZnO. Similarly, $\left[\mathrm{Zn}\left(\mathrm{H}_{2}\right.\right.$ biim $)($ bpy $\left.) \mathrm{H}_{2} \mathrm{O}\right]\left(\mathrm{NO}_{3}\right)_{2}$, $\mathrm{Zn}(\mathrm{TPP})(\mathrm{IQNO}), \mathrm{Zn}(\mathrm{bba})_{2}$ (phen) show analogous performance (where $\mathrm{H}_{2}$ biim = bis(benzimidazole), bpy $=4,4^{\prime}$-bipyridyl, TPP $=$ tetraphenylporphyrin, $\mathrm{IQNO}=$ iso-quinoline $\mathrm{N}$-oxide, $\mathrm{bba}=$ 2-benzoylbenzoate and phen $=1,10$-phenanthroline). ${ }^{35}$

The triphenylamine-based imidazole-containing tripodal ligand, TIPA; is an excellent fluorophore in many photoluminescent applications. ${ }^{36}$ In this study, its band gap, between the highest occupied molecular orbital (HOMO) and the lowest unoccupied molecular orbital (LUMO), has been calculated to be $4.1 \mathrm{eV}$. The HOMO and LUMO energy level difference of the MOFs corresponds to the MOF conduction band valence energy level difference. When coordinated to $\mathrm{Zn}$ (II) the resulting polymer environment sharply reduces the band gap to $3.25 \mathrm{eV}$. The narrower band gap explains the excellent photocatalytic performance of the Zn-TIPA coordination polymer. A mechanistic study is undertaken towards explaining the enhanced photocatalytic performance. The $\mathrm{Zn}^{2+}$ complex has a dramatically smaller band gap by almost $1 \mathrm{eV}$ in comparison to the band gap of the florescent ligand, a reduction of $30 \%$. A narrow band gap for fluorophores is a necessary requirement for efficient photocatalysis.

We wish to report that a novel Zn-TIPA coordination polymer prepared in this study also exhibits selective photoluminescent sensing properties for nitromethane (NM) among nine other polar organic solvents as well as an antibiotic, ofloxacin (OFX). We have also studied if the Zn-MOF's is capable of adsorbing a number of common pollutant oxyanions such as the permanganate anion.

\section{Experimental section}

\section{Materials and methods}

TIPA was synthesized according to reported procedures. ${ }^{37}$ Reagents (such as $\mathrm{H}_{2} \mathrm{seb}$ ) and solvents were obtained from commercial sources and were used as received without further purification. Double-deionised water was used in hydrothermal synthesis. Fourier-transform infrared (FTIR) spectra (Fig. S3†) were obtained from $\mathrm{KBr}$ pellets in the range of $4000-400 \mathrm{~cm}^{-1}$ using an FTS 3000 (DIGILAB) spectrometer. Thermogravimetric analysis (TGA) data were obtained using a PerkinElmer Pyris Diamond TG/DTA TG-7 Thermal Analyzer. Experiments were performed in the $25-800{ }^{\circ} \mathrm{C}$ temperature range in a nitrogen atmosphere with a heating rate of $10{ }^{\circ} \mathrm{C} \mathrm{min}^{-1}$. Morphology analysis was performed using an ULTRA Plus scanning electron microscope (SEM, Germany). Single-crystal X-ray diffraction was carried out using a Bruker Apex Smart CCD diffractometer equipped with a graphite crystal monochromator at $293 \mathrm{~K}$.

Data collection, cell refinement and data reduction were performed with CrysAlis PRO from Agilent Technologies. The structure was solved by direct methods using the SHELX-97 program, ${ }^{38}$ and final refinement performed by the full-matrix least-squares method with anisotropic thermal parameters for non-hydrogen atoms on $F^{2}$. The non-hydrogen atoms were located in successive Fourier maps and refined anisotropically, and the $\mathrm{H}$ atoms were placed in calculated positions and refined isotropically with fixed thermal parameters. Although, electron densities attributable to a highly disordered nitrate anion could be observed in the Fourier maps, no satisfactory disorder model could be achieved. In addition, unaccounted for electron densities were also observed throughout the map. The electron densities associated with the nitrate and other atoms were removed by the SQUEEZE/PLATON program, which led to a significantly better refinement of the overall structure. Specifically, the calculated scattering of 265 electrons in a void volume of $703 \AA^{3}$ per unit cell were assigned to $4 \mathrm{NO}_{3}{ }^{-}$anions and $14 \mathrm{H}_{2} \mathrm{O}$ molecules. Crystallographic data collection and refinement details are given in Table S1. $\dagger$ Selected bond distances and angles are listed in Table S2. $\dagger$ Crystallographic data for the structural analysis have been deposited with the Cambridge Crystallographic Data Centre, CCDC no. 1967331.

Powder X-ray diffraction (XRD) patterns were measured using a Philips PW 1710-BASED diffractometer at $293 \mathrm{~K}$. Simulated powder XRD pattern for $\left\{\left[\mathrm{Zn}(\mathrm{TIPA})(\mathrm{seb})_{0.5}\right]\left(\mathrm{NO}_{3}\right)\right.$. 
$\left.3.5 \mathrm{H}_{2} \mathrm{O}\right\}_{n} 1$ (Fig. S8 $\dagger$ ) was obtained from the final CIF file using the Mercury 2.0 program. $^{39}$ Solid-state fluorescent emission spectra were obtained at ambient temperature using a LS-55 (PE USA Inc.) fluorescence spectrophotometer.

\section{Synthesis of $\left\{\left[\mathrm{Zn}(\mathrm{TIPA})(\mathrm{seb})_{0.5}\right]\left(\mathrm{NO}_{3}\right) \cdot 3.5 \mathrm{H}_{2} \mathrm{O}\right\}_{n}(\mathbf{1})$}

A mixture of $\mathrm{ZnNO}_{3} \cdot 6 \mathrm{H}_{2} \mathrm{O}(66.04 \mathrm{mg} 0.2 \mathrm{mmol})$, TIPA $(66.47 \mathrm{mg}$, $0.15 \mathrm{mmol}$ ), $\mathrm{H}_{2} \mathrm{seb}$ ( $30.33 \mathrm{mg}, 0.15 \mathrm{mmol}$ ), DMF $(2 \mathrm{~mL})$ and $\mathrm{H}_{2} \mathrm{O}$ $(6 \mathrm{~mL})$ was sealed in a Teflon-lined stainless steel container and heated at $105{ }^{\circ} \mathrm{C}$ for 3 days. When cooled to room temperature colorless cubic crystals of 1 were obtained in $53 \%$ yield. Anal. calcd for $\mathrm{C}_{32} \mathrm{H}_{36} \mathrm{~N}_{8} \mathrm{O}_{8.5} \mathrm{Zn}$ : C, 52.39; H, 4.91; N, 15.28\%. Found: C, 51.26; H, 4.86; N, 15.37\%. IR (KBr pellet, $\mathrm{cm}^{-1}$ ): $3458(\mathrm{~m})$, $3118(\mathrm{~m}), 2923(\mathrm{~m}), 1665\left(\mathrm{~s}, \nu_{\text {asym }}\left(\mathrm{CO}_{2}\right)\right), 1513(\mathrm{~s}), 1407(\mathrm{~m}$, $\left.\nu_{\text {sym }}\left(\mathrm{CO}_{2}\right)\right), 1279(\mathrm{~s}), 1128(\mathrm{~m}), 1053(\mathrm{~s}), 962(\mathrm{~m}), 751(\mathrm{w}), 646(\mathrm{~m})$, $548(\mathrm{~m})$.

The dicarboxylate ligands are expected to act as $\mu_{2}-\eta^{1}-\eta^{0}-$ $\eta^{1}-\eta^{0}$ bridges as the $\Delta \nu$ values are observed at 240 and $258 \mathrm{~cm}^{-1}$. The crystallographic structure is consistent with the IR spectra, although the sebacate dianion coordinates to the metal antisymmetrically (see below).

\section{Results and discussion}

\section{Crystal structure of $\left\{\left[\mathrm{Zn}(\mathrm{TIPA})(\mathrm{seb})_{0.5}\right]\left(\mathrm{NO}_{3}\right) \cdot 3.5 \mathrm{H}_{2} \mathrm{O}\right\}_{n}(1)$}

Complex 1 crystallizes in the centrosymmetric monoclinic space group $P 2_{1} / n$ and the asymmetric unit consists of one $\mathrm{Zn}^{2+}$ cation, one TIPA ligand, a half $\mathrm{seb}^{2-}$ anion. A two fold axis of symmetry passes through the central $\mathrm{C}-\mathrm{C}$ bond of the sebacate ligand. All atoms of the cation are located on general positions. The TIPA ligand coordinates through all of its imidazole $\mathrm{N}$ atoms binding three different symmetrically equivalent $\mathrm{Zn}$ atoms. Therefore the zinc is five-coordinate and its geometry distorted square pyramidal with the N's of three different TIPA ligands occupying one face of the square pyramid as shown in Fig. 2a. Each of the carboxylates coordinates to the metal ion antisymmetrically with two significantly different $\mathrm{Zn}-\mathrm{O}$ bond distances, 2.110(12) and 2.477(11) A. The dinucleating $\mu_{4}-\eta^{2}-\eta^{2}$ and trinucleating $\mu_{3}-\eta^{1}-\eta^{1}-\eta^{1}$ coordination modes of the seb ${ }^{2-}$ and TIPA ligands lead to a fascinating three dimensional network structure. The structure features channels formed exclusively by the TIPA ligands and $\mathrm{Zn}^{2+}$ cations (Fig. 2b). The channels are further linked together by the dinucleating $\left(\mu_{4}-\eta^{2}-\right.$ $\eta^{2}$ ) seb $^{2-}$ ligands (Fig. 2c). A simplified view of the network with the representation of the TIPA and $\mathrm{seb}^{2-}$ ligands and the $\mathrm{Zn}^{2+}$ cation as 3-, 2- and 4-connected nodes reveals a two-fold interpenetrating diamondoid network as shown in Fig. 2d, The Schläfli symbol for the network is $\left\{3^{3} \cdot 4^{3} \cdot 5^{4} \cdot 6^{4} \cdot 7\right\}$ as determined by the TOPOS software. As outlined in the experimental section, scattering due to nitrate anions and a number of solvated water molecules is observed during the refinement of the structure, and could not be adequately modeled. We suggest that the anion and water solvates are highly disordered over a large volume. We also point out that the water solvates are readily lost on drying the product as confirmed by the elemental analysis data. The ready loss of water solvates also explains the host- guest properties of $\mathbf{1}$. SEM images of complex $\mathbf{1}$ are shown in Fig. S9. $\dagger$ The material exhibits a uniformly distributed and loose block morphology. The SEM image with $2 \mu \mathrm{m}$ scale plate, shows random-shaped aggregation composed by many macroscopic tiny balls.

\section{Thermogravimetric analysis}

Crystals of 1 are quite stable showing no sign of decomposition or disintegration under ambient conditions. TGA data (Fig. S2, ESI $\dagger$ ) were measured in the $25-800{ }^{\circ} \mathrm{C}$ temperature range, in order to determine the robustness of the 3D framework present in the crystals. The TGA data reveal a gradual loss of mass corresponding to the loss of the solvated water molecules in the $100-200{ }^{\circ} \mathrm{C}$ temperature region. This gradual loss over a wide temperature range are consistent with the presence of strong $\mathrm{H}$ bonding interactions deduced from the crystallographic data analysis. Complex 1 appears to regain its MOF architecture up to $c a .300{ }^{\circ} \mathrm{C}$ and exhibits a one-step or two closely-spaced steps of mass loss due to the decomposition of the TIPA ligand. We conclude that the multiply bridged network framework is robust up to $T>300{ }^{\circ} \mathrm{C}$.

\section{Luminescence properties}

Considering that $\mathrm{d}^{10}$ metal complexes usually exhibit excellent luminescent properties, the emission of $\mathbf{1}$ was investigated in the solid state at room temperature. Upon excitation at $276 \mathrm{~nm}$, the complex exhibits an intense emission peak centered at $c a$. $392 \mathrm{~nm}$. To gain further insight, the luminescence spectrum was also measured for the free TIPA ligand at the excitation wavelength set at $276 \mathrm{~nm}$. The ligand emits a broad emission band from 370 to $550 \mathrm{~nm}$ with the maximum $\left(\lambda_{\max }\right)$ being $415 \mathrm{~nm}$. The emission band can be ascribed to $\pi^{*} \rightarrow \pi$ or $\pi^{*} \rightarrow$ $\mathrm{n}$ transitions within the molecular orbital manifolds of the imidazolyl and phenyl rings of TIPA moieties. Therefore, we conclude that the luminescent properties of the TIPA ligand is preserved upon complexation with the $\mathrm{Zn}^{2+}$ ions. However, the metal complex exhibits responsive emission properties in the presence of certain organic compounds. The blue shift of emission bands observed for $\mathbf{1}$ is due to the coordination interactions between $\mathrm{Zn}^{2+}$ and the added organic compounds (Fig. 3 and 4).

\section{Optical band gaps}

Since the $\mathrm{Zn}^{2+}$ complex 1 has potential application in semiconductor materials, we measured its optical diffuse-reflection. The absorption data $(F=\alpha / S)$ were calculated from the reflectance using the Kubelka-Munk function: $F=\frac{(1-R)^{2}}{2 R}$, where $\alpha=$ absorption, $S=$ scattering coefficient, and $R=$ reflectance of an infinitely thick layer at a given wavelength. The energy band gap, $E_{\mathrm{g}}$, is defined as the intersection point among the energy axis and line extrapolated of the linear portion. The $E_{\mathrm{g}}$ value obtained for the complex is $3.25 \mathrm{eV}$. The reflectance spectrum shows that the optical band gap and semiconductor behaviour exist in this complex. The band gap also suggests that $\mathbf{1}$ may 


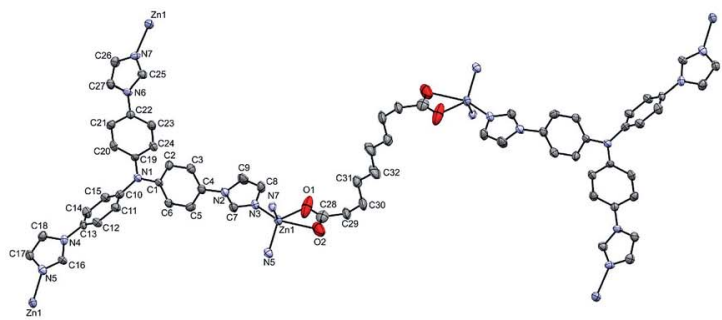

(a)

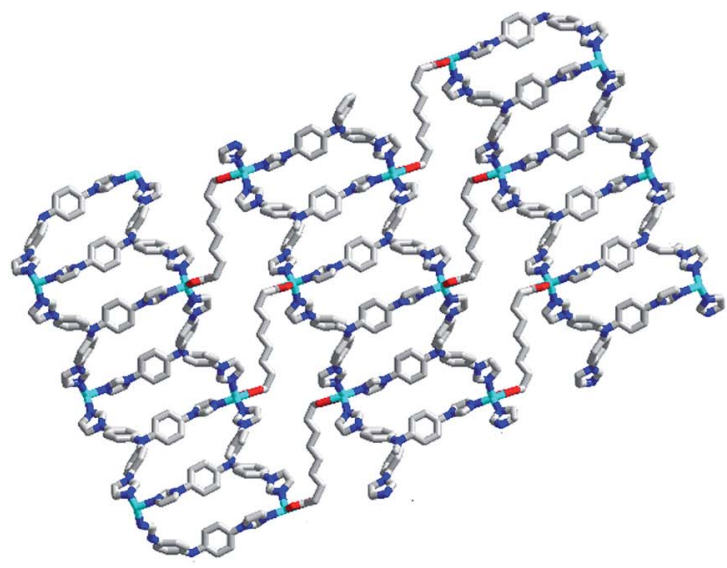

(c)

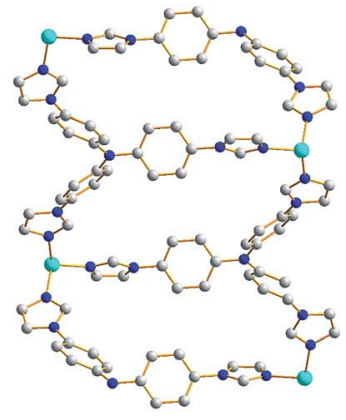

(b)

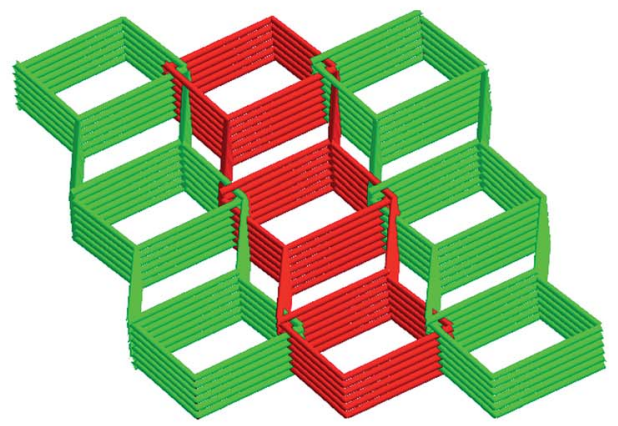

(d)

Fig. 2 (a) Coordination environment of the $\mathrm{Zn}$ atom in 1. (b) Channels formed by the TIPA ligands and $\mathrm{Zn}^{2+}$ cations, (c) Seb ${ }^{2-}$ ligands bridging $\mathrm{Zn}$-TIPA channels forming additional channels. (d) Two-fold interpenetrating diamondoid network.

respond to UV light and possess the potential capacity for photocatalytic reactions.

To investigate the HOMO to LUMO energy band gap of solo ligand compounds, density functional theory (DFT) computations were carried out for pure TIPA molecules. All computations were performed with the Gaussian09 software package using the density functional B3LYP method 13 and the standard 6-311++G(d,p) basis set. ${ }^{40-42}$

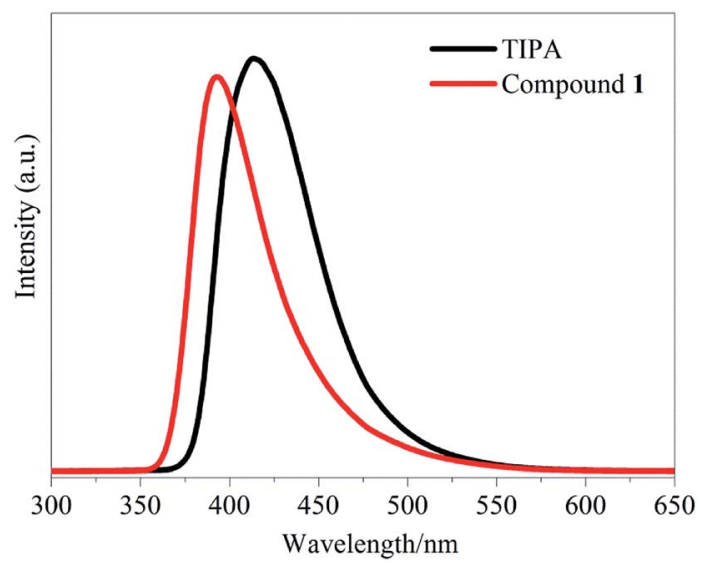

Fig. 3 The emission spectra of compound and TIPA in solid state $\left(\lambda_{\text {ex }}\right.$ $=276 \mathrm{~nm}$ ).
As it can be seen from Fig. 5, the energy band gap for the free TIPA based on the calculated HOMO $(-5.825 \mathrm{eV})$ to LUMO $(-1.724 \mathrm{eV})$ molecular energy levels is $4.10 \mathrm{eV}$. The study also reveals that when TIPA is coordinated to $\mathrm{Zn}^{2+}$, the energy band gap can be dramatically reduced by $30 \%$ to $3.25 \mathrm{eV}$. A detailed rationale for $\mathrm{Zn}^{2+}$ narrowing the band gaps by the formation of metal-organic complexes is given as follows:

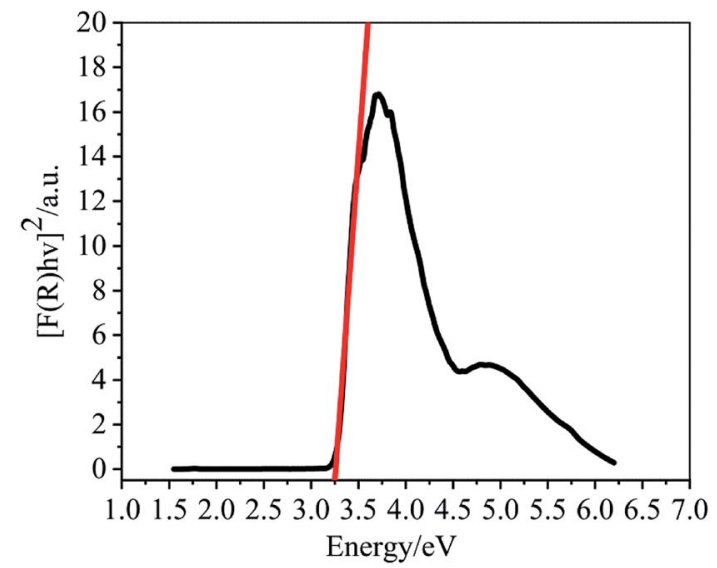

Fig. 4 Solid-state optical diffuse-reflection spectrum for 1 at room temperature. 


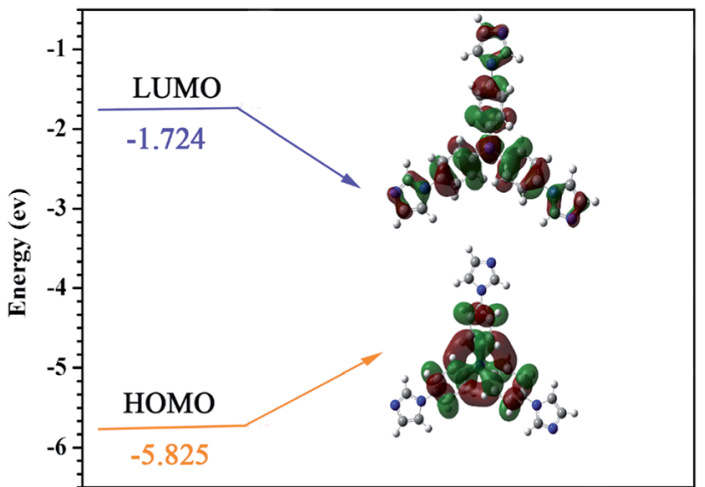

Fig. 5 Calculated HOMO and LUMO energy levels for ligand TIPA.

The $\mathrm{Zn}^{2+}$ cation plays an important role in ligand to metal charge transfer (LMCT) as this occurs with the charge transition on the empty p orbitals from the oxygen of the dicarboxylate ligand and nitrogen of the TIPA ligand to the metal centre. ${ }^{43}$ The HOMO orbital of the metal complex consists mainly of $2 p$ (valence band) empty orbitals of $\mathrm{O}$ and $\mathrm{N}$ atoms, ${ }^{44}$ whilst the LUMO orbital of the complex is mainly composed of an empty orbit (guide band orbit) of the $\mathrm{Zn}$ atom. ${ }^{44}$ The splitting effect on the charge transfer from the $\mathrm{p}$ orbitals of TIPA nitrogen atoms to the empty guide band orbit of the $\mathrm{Zn}^{2+}$ cation has significantly reduced the energy level of LUMO in the metal complex. Thus, under the influence of the LMCT, the HOMO to LUMO energy band gap for $\mathrm{Zn}^{2+}-\mathrm{MOF}$ is much smaller compared to that of the free TIPA ligand.

\section{Photocatalysis properties}

The $\mathrm{Zn}^{2+}-\mathrm{MOF}$ complex 1 was screened for its contribution to the photo-degradation of a variety of dyes. The dyes studied were rhodamine B (RHb), crystal violet, fuchsin basic, malachite green oxalate (MGO) and methyl orange (MO). (Fig. S1, ESI $\dagger$ ) The photo-degradation experiments were performed for $0.01 \mathrm{mM}$ solutions of the dyes in a $3 \mathrm{~mL}$ cuvette by monitoring the intensity of one of the peaks in their UV-vis spectra in the presence of the MOF complex ( $1 \mathrm{mg}$ ) or aq. $\mathrm{H}_{2} \mathrm{O}_{2}$ (30\%, 1 drop). The experiments were also repeated after irradiation of the dye solutions containing the MOFs with UV light for $30 \mathrm{~min}$. The data measured reveal that complex $\mathbf{1}$ is of assistance in the degradation reactions. Significantly, enhanced degradation is observed for MGO when both complex 1 and $\mathrm{H}_{2} \mathrm{O}_{2}$ are present and when the mixture is irradiated with UV light. The spectra measured for the dyes under various conditions are given in Fig. 6.

The degradation rate was monitored in the presence of both 1 and $\mathrm{H}_{2} \mathrm{O}_{2}$, and with the irradiation of UV light. The study revealed that the absorption peak due to MGO significantly reduced in intensity as the photocatalytic reaction progressed within a short time period of 35 min (Fig. 7).

A complete degradation mechanism for the combined effect of the photocatalyst in the degradation of MGO can be explained by eqn (1)-(5).

$$
\text { Zn-MOF photocatalyst } \mathbf{1}+h \nu \rightarrow \mathrm{e}^{-}+\mathrm{h}^{+}
$$

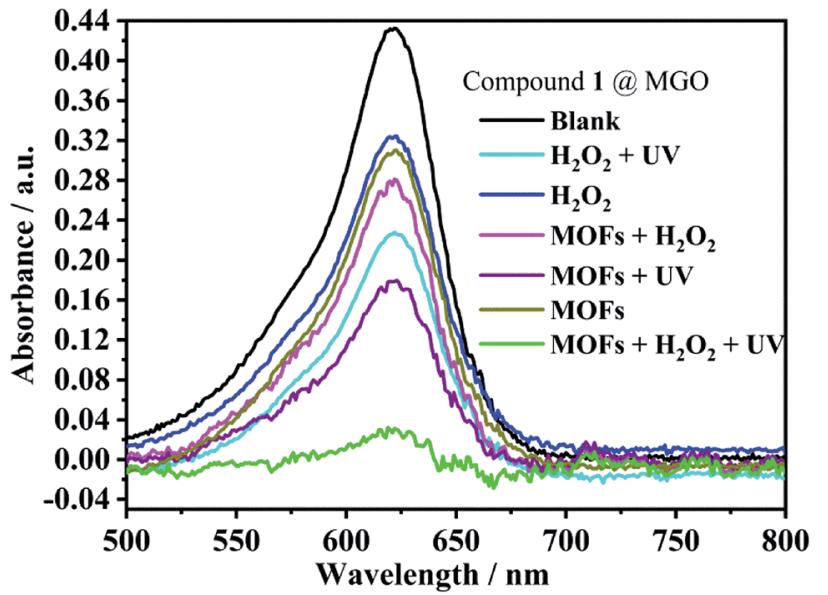

Fig. 6 Photocatalytic degradation of malachite green oxalate (MGO) catalyzed by 1 under various conditions.

$$
\begin{gathered}
\text { MGO dyes (MD) }+\mathrm{h}^{+} \rightarrow \mathrm{MD}^{+} \\
\mathrm{O}_{2}+\mathrm{e}^{-} \rightarrow \cdot \mathrm{O}_{2}{ }^{-} \\
\mathrm{H}_{2} \mathrm{O}_{2}+\cdot \mathrm{O}_{2}^{-} \rightarrow \cdot \mathrm{OH}+\mathrm{OH}^{-}+\mathrm{O}_{2} \\
\mathrm{MD}^{+}+\left(\mathrm{h}^{+}+\cdot \mathrm{OH}+\cdot \mathrm{O}_{2}^{-}\right) \rightarrow \text { degradation products }
\end{gathered}
$$

During irradiation under UV light, electrons $\left(\mathrm{e}^{-}\right)$in the HOMO (valence band, VB) were excited to the LUMO (conduction band, CB), and equal numbers of positive vacancies (holes, $\mathrm{h}^{+}$) were left in the VB. Initially, oxygen radicals $\left(\cdot \mathrm{O}_{2}{ }^{-}\right)$are generated by combining the electrons and $\mathrm{O}_{2}$ absorbed on the surfaces of the Zn-MOF photocatalyst. $\mathrm{O}_{2}$ is reduced into $\cdot \mathrm{O}_{2}{ }^{-}$ with the combination of electrons $\left(\mathrm{e}^{-}\right)$, which further transformed into hydroxyl radicals $(\cdot \mathrm{OH})$. Such hydroxyl radicals are known to be highly efficient in the degeneration of malachite green oxalate. It is notable that $\mathrm{H}_{2} \mathrm{O}_{2}$ provides part of the $\mathrm{O}_{2}$ and hydroxyl $\left(\mathrm{OH}^{-}\right)$adsorbed on the surfaces of the $\mathrm{Zn}-\mathrm{MOF}$ catalyst 1 and significantly accelerates the photocatalytic reaction.

From the perspective of molecular orbital study, the irradiation of MOF 1 by UV light must cause an empty orbital transition of the $2 p$ electrons of the ligand $\mathrm{O}$ or $\mathrm{N}$ atoms to the $\mathrm{Zn}^{2+}$ cation, which will be the LMCT transition. According to the representation, the process of semiconductor photocatalysis can be regarded as the electrons that transition to the $\mathrm{Zn}^{2+}$ empty orbit as photogenerated electrons, and the empty orbitals left behind by the electronic transition associated with the $2 \mathrm{p}$ of $\mathrm{O}$ or $\mathrm{N}$ atoms as the photogenerated holes. The HOMO orbital that loses electrons must capture an electron from the water molecule back to the ground state. Correspondingly, a molecule that loses an electron is oxidized into the active species, $\cdot \mathrm{OH}$ radical. Thus the highly reactive $\cdot \mathrm{OH}$ radical can effectively oxidize organic dye molecules to complete the photocatalytic process.

\section{Sensing of organic solvents}

Nitromethane is listed as a group 2B carcinogen by the World Health Organization's International Agency for Research on 
(a)
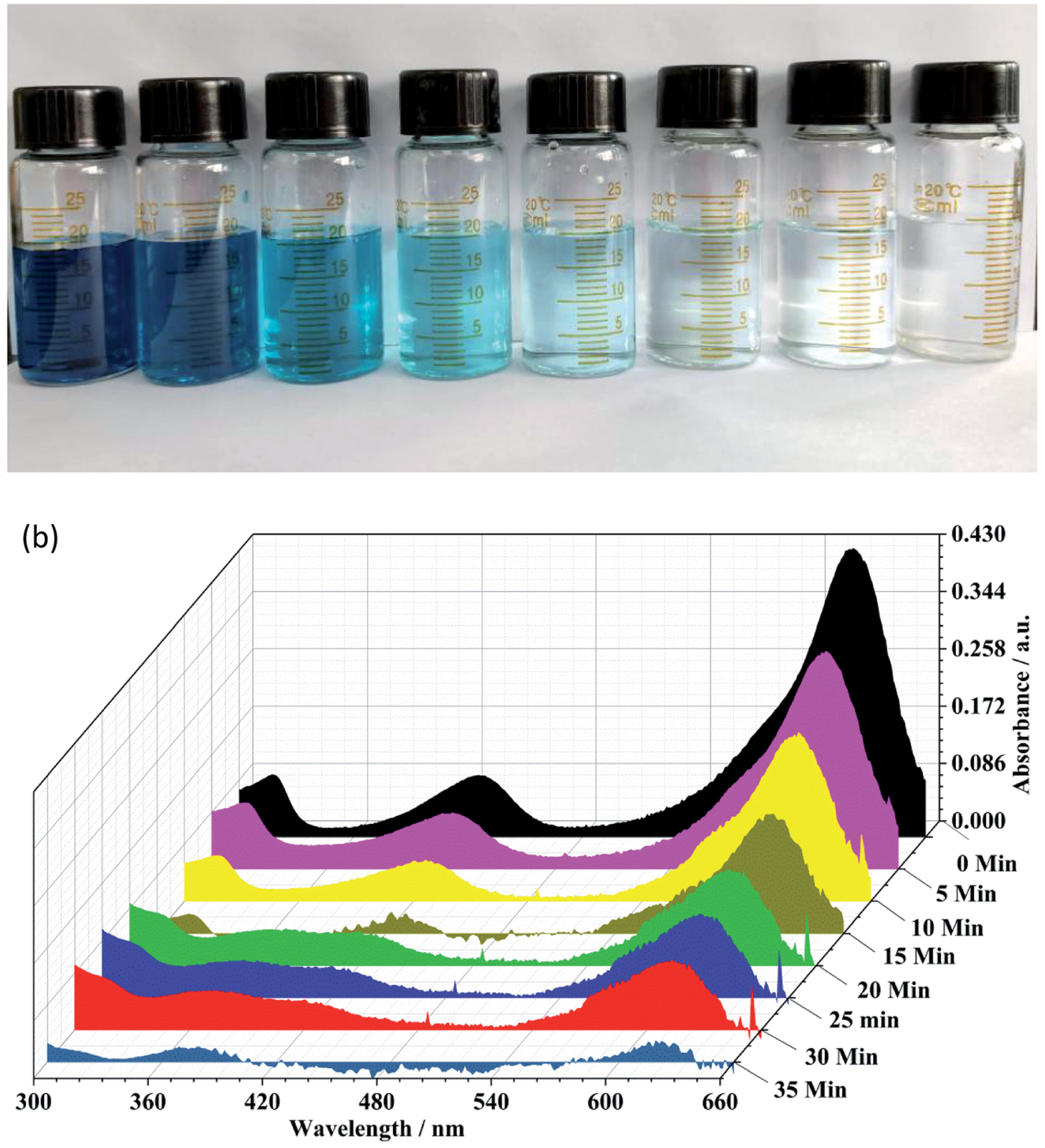

Fig. 7 (a) Photograph of photocatalytic decomposition of $M G O$ by 1 in the presence of $\mathrm{H}_{2} \mathrm{O}_{2}$ and UV light. (b) 3D Plots of UV-vis spectra showing the photo-degradation of MGO over time.

Cancer. Therefore, towards evaluating the ability of the current Zn-MOF complex 1 to detect of nitromethane we have studied the effect of various organic solvents on the emission spectra of $\mathbf{1}$, and observe that the complex is capable of detecting nitromethane as discussed below.

The solvents included in the study are dimethylformamide (DMF), 1,4-dioxane, dimethylsulfoxide (DMSO), dimethylacetamide (DMA), ethanol $\left(\mathrm{CH}_{3} \mathrm{CH}_{2} \mathrm{OH}\right)$, methanol $\left(\mathrm{CH}_{3} \mathrm{OH}\right)$, acetonitrile $\left(\mathrm{CH}_{3} \mathrm{CN}\right)$, 1-methyl-2-pyrrolidinone (NMP), acetone and nitromethane (NM). Each sample was tested for fluorescence intensity, as shown in Fig. 8.

The luminescence sensing studies indicate that complex 1 might have potential use as a highly sensitive probe for selective detection of NM.
Additional experiments were also carried out to determine the quenching efficiency of NM by varying the volume of it added to a suspension of $\mathbf{1}$. The spectra measured are shown in Fig. S5. $\dagger$ When $2 \mu \mathrm{L}$ of NM was added, a decrease in relative intensity from $100 \%$ to $60 \%$ was observed. For the addition of 4 $\mu \mathrm{L}$ of $\mathrm{NM}$, the emission intensity decreased sharply, and a further rise in the volume of NM, added gradually, reduced the emission intensity, with $50 \mu \mathrm{L}$ of NM completely quenching the fluorescence of the suspension.

The quenching effects were treated quantitatively, with the Stern-Volmer equation:

$$
I_{0} / I=1+K_{\mathrm{sv}}[\mathrm{M}]
$$




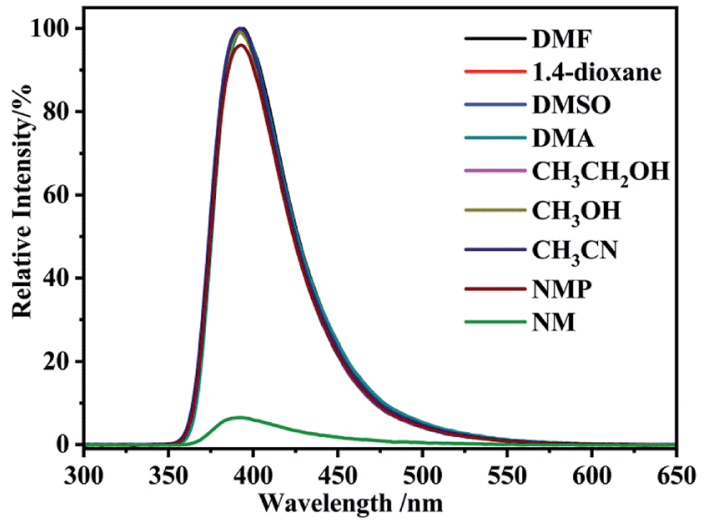

(a)

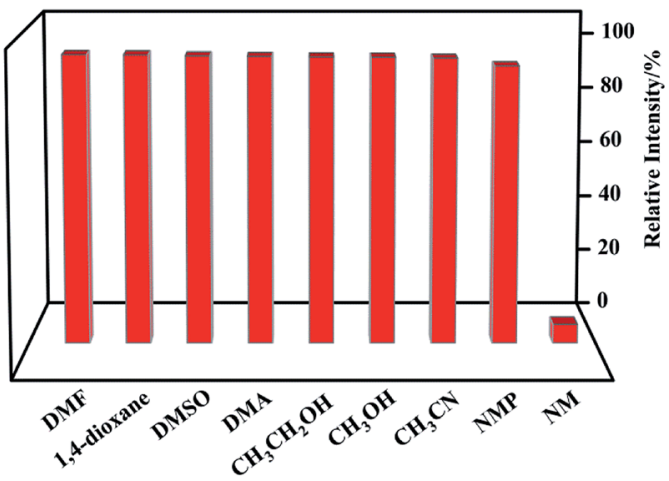

(b)

Fig. 8 Photoluminescence spectra (a) and luminescence intensities (b) for a suspension of 1 after the suspension is introduced into various pure solvents.

where $I_{0}$ and $I$ are the luminescence intensities of complex 1 and the NM-incorporated $\mathbf{1}$, respectively. $K_{\mathrm{sv}}$ is the coefficient of the quenching effect for NM, and [M] is the concentration of NM. (Fig. S5, ESI $\dagger$ ).

\section{Sensing of antibiotics}

The sensing of various antibiotics by 1 was also investigated. The studies were performed by the addition of $30 \mu \mathrm{L}$ of $0.01 \mathrm{M}$ solutions of nine antibiotic compounds: Roxithromycin (RXM), Amoxicillin (AMX), Thioridazine (TDZ), Dithiazoline (DTZ), Metronidazole (MDZ), Ornidazole (ODZ), Isonicotinylhydrazide (INH), Ridinilazole (RDZ) and Ofloxacin (OFX) to a $1 \mathrm{mg} \mathrm{mL}{ }^{-1}$ suspension of the complex $\mathbf{1}$ at room temperature. We observed that the luminescence intensity of the mixture is heavily dependent on the nature of the antibiotics, and that OFX exhibited a high quenching effect on the luminescence of $\mathbf{1}$, revealing that complex 1 could be used as a sensor for OFX. The quenching effect of OFX was analysed using the Stern-Volmer equation. From the spectra measured, we calculate a $K_{\mathrm{sv}}$ value of $1.388 \times 10^{4}$ $\mathrm{M}^{-1}$ for $\mathbf{1}$, which is comparable to the value reported for a similar $\mathrm{d}^{10} \mathrm{Cd}-\mathrm{MOF}\left(1.16 \times 10^{4} \mathrm{M}^{-1}\right)$ for the sensing of antibiotic Metronidazole (MDZ). ${ }^{45}$ The luminescence sensing studies indicate that complex 1 may be used as a highly sensitive probe for selective detection of antibiotics OFX. (Fig. S6 and S7, ESI $\dagger$ ).

\section{Adsorption of permanganate ions on MOFs}

UV-vis spectroscopy was used to examine the extent of adsorption of the anions in the $\mathrm{Zn} \mathrm{MOF}$ complex. Aqueous solutions of $\mathrm{MnO}_{4}{ }^{-}$are deeply coloured and exhibit characteristic UV-vis spectra in the 300-400 nm, and 480-600 nm wavelength regions, respectively. The intensity of absorption is reduced when the anions adsorb to the MOF complexes that remain as solids in water due to their poor solubility in water. In a typical measurement, a UV-vis spectrum was measured for an aqueous $0.1 \mathrm{mM}$ solution of $\mathrm{KMnO}_{4}$, and additional spectra were measured after the addition of $1 \mathrm{mg}$ of the MOF complex. The spectra were measured every 10 minutes over a period of 1 hour. The UV-vis spectra for the permanganate solutions after the addition of $\mathbf{1}$ are shown in Fig. S4. $\dagger$ As can be seen from the spectra, complex 1 exhibits significant adsorption capability for the permanganate anion and reveals that the adsorption of the permanganate salt reaches equilibrium in 1 hour. The UV absorbance at the characteristic peak regions of 480-600 $\mathrm{nm}$ can be reduced by $80 \%$ relative intensity. Thus, complex 1 possesses a moderate ability to adsorb the oxyanion salt from aqueous solutions (Fig. S4, ESI $\dagger$ ).

\section{Conclusions}

This study has established that the $\mathrm{Zn}^{2+}$ cation dramatically lowers the florescent compound TIPA's HOMO to LUMO band gap through the building up of a $3 \mathrm{D}$ coordination polymer. This is the first report that demonstrates the coordination of a metal ion to a fluorophore ligand could narrow the band gap of the fluorophore in the coordination polymer. Specifically, we report that the $\mathrm{Zn}^{2+}$ coordination to TIPA dramatically narrows the band gap of the fluorescent ligand TIPA's HOMO to LUMO energy level difference to almost $1 \mathrm{eV}$, which is a total reduction of $30 \%$. A narrow band gap for fluorophores is a necessary requirement for efficient photocatalysis. Our investigation into the mechanism of the photocatalytic process reveals that the interactions between metal and ligand play an important role. The new zinc coordination polymer also shows selective photoluminescent sensing ability towards nitromethane among nine polar organic solvents and antibiotic ofloxacin via the luminescent quenching process. In addition, we observe that the coordination polymer is capable of adsorbing the permanganate anion, and could be applied as a crystalline sponge. These results provide important insights into the effects of the $\mathrm{Zn}^{2+}$ ion coordination on the photoluminescent properties of the TIPA ligand and the MOF complex's potential application in photocatalytic degradation of dyes, detection of nitromethane and ofloxacin and in the removal of pollutant oxyanion permanganate from wastewater.

\section{Conflicts of interest}

There are no conflicts to declare. 


\section{Acknowledgements}

This work is funded by the Wyoming NASA Space Grant Consortium, NASA Grant \#NNX15AI08H.

\section{References}

1 V. Katheresan, J. Kansedo and S. Y. Lau, J. Environ. Chem. Eng., 2018, 6, 4676-4697.

2 Y. Zhang, N. E. Almodovar-Arbelo, J. L. Weidman, D. S. Corti, B. W. Boudouris and W. A. Phillip, npj Clean Water, 2018, 1, 2 .

3 B. C. Hodges, E. L. Cates and J. H. Kim, Nat. Nanotechnol., 2018, 13, 642-650.

4 S. Kampouri, T. N. Nguyen, M. Spodaryk, R. G. Palgrave, A. Züttel, B. Smit and K. C. Stylianou, Adv. Funct. Mater., 2018, 28, 1806368.

5 D. Jiang, P. Xu, H. Wang, G. Zeng, D. Huang, M. Chen, C. Lai, C. Zhang, J. Wan and W. Xue, Coord. Chem. Rev., 2018, 376, 449-466.

6 C. Fan, Z. Zong, X. Zhang, C. Xu, Z. Zhu, X. Meng, S. Bi and Y. Fan, CrystEngComm, 2018, 20, 4973-4988.

7 W. J. Ji, R. Q. Hao, W. W. Pei, L. Feng and Q. G. Zhai, Dalton Trans., 2018, 47, 700-707.

8 D. Wang, F. Jia, H. Wang, F. Chen, Y. Fang, W. Dong, G. Zeng, X. Li, Q. Yang and X. Yuan, J. Colloid Interface Sci., 2018, 519, 273-284.

9 Y. Zhang, J. Zhou, W. Cai, J. Zhou and Z. Li, Appl. Surf. Sci., 2018, 430, 549-560.

10 Y. Lin, H. Wan, F. Chen, X. Liu, R. Ma and T. Sasaki, Dalton Trans., 2018, 47, 7694-7700.

11 M. Oveisi, M. Alinia Asli and N. M. Mahmoodi, Inorg. Chim. Acta, 2019, 487, 169-176.

12 X. Liu, B. Liu, G. Li and Y. Liu, J. Mater. Chem. A, 2018, 6, 17177-17185.

13 N. Manjula, G. Selvan and A. R. Balu, J. Mater. Sci.: Mater. Electron., 2017, 29, 3657-3664.

14 C. Belabed, B. Bellal, A. Tab, K. Dib and M. Trari, Optik, 2018, 160, 218-226.

15 S. Aghakhaninejad, R. Rahimi and S. Zargari, Proceedings, 2018, 9, 52.

16 A. Z. M. Mainul Islam Mazumder, Am. J. Phys. Chem., 2018, 7, 6. 17 C. V. Reddy, K. R. Reddy, V. V. N. Harish, J. Shim, M. V. Shankar, N. P. Shetti and T. M. Aminabhavi, Int. J. Hydrogen Energy, 2019, DOI: 10.1016/j.ijhydene.2019.02.144.

18 S. Jayapandi, D. Lakshmi, S. Premkumar, P. Packiyaraj and K. Anitha, Mater. Lett., 2018, 218, 205-208.

19 S. Ramachandran and A. Sivasamy, J. Environ. Chem. Eng., 2018, 6, 3770-3779.

20 S. K. Warkhade, S. P. Zodape, U. R. Pratap and A. V. Wankhade, J. Mol. Liq., 2019, 279, 434-443.

21 P. B. Santos, J. J. Santos, C. C. Corrêa, P. Corio and G. F. S. Andrade, J. Photochem. Photobiol., A, 2019, 371, 159-165.

22 O. Monfort and G. Plesch, Environ. Sci. Pollut. Res. Int., 2018, 25, 19362-19379.
23 V. P. Parvathi, R. Parimaladevi, V. Sathe and M. Umadevi, Appl. Surf. Sci., 2019, 473, 864-872.

24 J.-P. Zou, Y. Chen, M. Zhu, D. Wang, X.-B. Luo and S.-L. Luo, Semiconductor-Based Nanocomposites for Photodegradation of Organic Pollutants, in In Micro and Nano Technologies, Nanomaterials for the Removal of Pollutants and Resource Reutilization, ed. X. Luo and F. Deng, Elsevier, 2019, pp. 2558, ISBN 9780128148372, DOI: 10.1016/b978-0-12-8148372.00002-0.

25 Y.-H. Chiu, T.-F. M. Chang, C.-Y. Chen, M. Sone and Y.-J. Hsu, Catalysts, 2019, 9, 430.

26 J. Feng, S. Xiong and Y. Wang, Compos. Commun., 2019, 12, 39-46.

27 H.-J. Wang, Y. Cao, L.-L. Wu, S.-S. Wu, A. Raza, N. Liu, J.-Y. Wang and T. Miyazawa, J. Environ. Chem. Eng., 2018, 6, 6771-6779.

28 C. N. Peter, W. W. Anku, R. Sharma, G. M. Joshi, S. K. Shukla and P. P. Govender, Ionics, 2018, 25, 327-339.

29 A. R. Prasad, P. Rugmini Ammal and A. Joseph, Mater. Res. Bull., 2018, 102, 116-121.

30 Bhawna, B. P. Majee, V. Choudhary, R. Prakash and A. K. Mishra, AIP Conf. Proc., 2019, 2100, 020073.

31 M. Ebrahimi, S. Yousefzadeh, M. Samadi, C. Dong, J. Zhang and A. Z. Moshfegh, Appl. Surf. Sci., 2018, 435, 108-116.

32 S. Sohrabnezhad and S. Taghaddosnezhad, Appl. Clay Sci., 2018, 157, 130-138.

33 Z. Wu, X. Chen, X. Liu, X. Yang and Y. Yang, Nanoscale Res. Lett., 2019, 14, 147.

34 J.-C. Jin, J. Wu, W.-C. Liu, A.-Q. Ma, J.-Q. Liu, A. Singh and A. Kumar, New J. Chem., 2018, 42, 2767-2775.

35 Y.-J. Yang, F.-S. Wang, D. Liu and G.-H. Cui, Inorg. Chem. Commun., 2019, 100, 60-63.

36 X. Zhang, Z. J. Wang, S. G. Chen, Z. Z. Shi, J. X. Chen and H. G. Zheng, Dalton Trans., 2017, 46, 2332-2338.

37 H. Wu, H. Y. Liu, Y. Y. Liu, J. Yang, B. Liu and J. F. Ma, Chem. Commun., 2011, 47, 1818-1820.

38 G. M. Sheldrick, Acta Crystallogr., Sect. C: Struct. Chem., 2015, 71, 3-8.

39 C. F. Macrae, I. J. Bruno, J. A. Chisholm, P. R. Edgington, P. McCabe, E. Pidcock, L. Rodriguez-Monge, R. Taylor, J. van de Streek and P. A. Wood, J. Appl. Crystallogr., 2008, 41, 466-470.

40 A. D. Becke, J. Chem. Phys., 1993, 98, 5648-5652.

41 M. J. Frisch, G. W. Trucks, H. B. Schlegel, G. E. Scuseria, M. A. Robb, J. R. Cheeseman, G. Scalmani, V. Barone, G. A. Petersson, H. Nakatsuji, X. Li, M. Caricato, A. V. Marenich, J. Bloino, B. G. Janesko, R. Gomperts, B. Mennucci, H. P. Hratchian, J. V. Ortiz, A. F. Izmaylov, J. L. Sonnenberg, Williams, F. Ding, F. Lipparini, F. Egidi, J. Goings, B. Peng, A. Petrone, T. Henderson, D. Ranasinghe, V. G. Zakrzewski, J. Gao, N. Rega, G. Zheng, W. Liang, M. Hada, M. Ehara, K. Toyota, R. Fukuda, J. Hasegawa, M. Ishida, T. Nakajima, Y. Honda, O. Kitao, H. Nakai, T. Vreven, K. Throssell, J. A. Montgomery Jr, J. E. Peralta, F. Ogliaro, M. J. Bearpark, J. J. Heyd, E. N. Brothers, K. N. Kudin, V. N. Staroverov, T. A. Keith, R. Kobayashi, J. Normand, K. Raghavachari, A. P. Rendell, 
J. C. Burant, S. S. Iyengar, J. Tomasi, M. Cossi, J. M. Millam, M. Klene, C. Adamo, R. Cammi, J. W. Ochterski, R. L. Martin, K. Morokuma, O. Farkas, J. B. Foresman and D. J. Fox, Gaussian 16 Rev. B.01, Wallingford, CT, 2016.

42 H. Kameo, S. Ishii and H. Nakazawa, Dalton Trans., 2012, 41, 8290-8296.
43 K. Kluska, J. Adamczyk and A. Krężel, Coord. Chem. Rev., 2018, 367, 18-64.

44 T. D. Pasatoiu, A. M. Madalan, M. U. Kumke, C. Tiseanu and M. Andruh, Inorg. Chem., 2010, 49, 2310-2315.

45 H. He, Y. Q. Xue, S. Q. Wang, Q. Q. Zhu, J. Chen, C. P. Li and M. Du, Inorg. Chem., 2018, 57, 15062-15068. 